\title{
Luis Buñuel: trascendiendo el tópico
}

\author{
Dr. Manuel Carlos Fernández Sánchez \\ Profesor de la Facultad de Ciencias de la Información de Sevilla.
}

\section{RESUMEN}

En 1.900 nace el cineasta Luis Buñuel en Calanda, Aragón. En el año 2.000 se celebra en distintos ámbitos cinematográficos y televisivos de todo el mundo el centenario de su nacimiento. Festivales de cine, cadenas de televisión por satélite u onda hertziana, periódicos y revistas se hacen eco de la enorme trascendencia del lenguaje cinematográfico buñueliano. Este estudio sobre la última de sus películas rodada en Andalucía, concretamente en Sevilla, pretende aportar un nuevo análisis sobre esta obra que trascendió el tópico andaluz.

\begin{abstract}
ABSTRAC
In 1900 the film director Luis Buñuel is born in Calanda, Aragón. In 2000, it took place the centennial of his birth in different film and television environments in all over the world. The transcendency of film languaje used by Buñuel has been anlysed in cinema festivals, television, newspapers and magazines. This study, focus on his last movies filmed in Andalusia, concretely in Seville, it seeks to contribute with a new analysis on this work that transcended the Andalusian topic.
\end{abstract}

Palabras claves: Luis Buñuel/Lenguaje cinematográfico/Andalucía/Tópico.

Key Words: Luis Buñuel/Film languaje/Andalusia/Topic.

\section{Primeras aproximaciones a Andalucía}

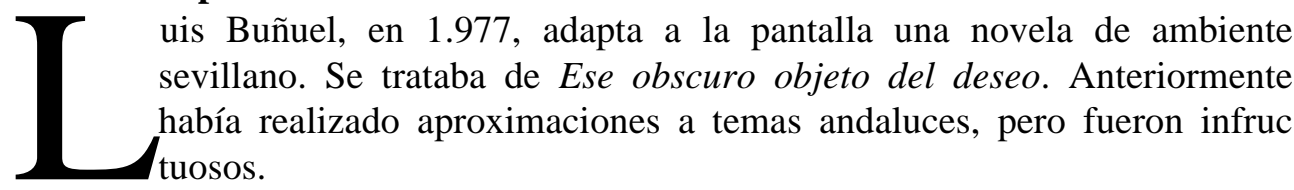

El celebrado, polémico y estudiado cortometraje del director de Calanda $U n$ chien andalou (Un perro andaluz), ese navajazo cinematográfico escrito en colaboración con Salvador Dalí y realizado en 1.928, de temática andaluza únicamente tiene el título, a pesar de que sus significados son ricos, ambiguos y polivalentes. En Un perro andaluz no había ni perros, ni andaluces, y sus imágenes no podían interpretarse como símbolos de nada de ello. Por lo tanto nadie ha de llamarse a engaño pretendiendo analizarla bajo una óptica andaluza. 
En 1.930 Buñuel barajó los títulos de «La bestia andaluza» y «Abajo la Constitución» para un nuevo filme que finalmente llamaría L'Age d'or. Sería pues otro intento de aproximación, lejano y surrealista, para una temática sobre Andalucía.

En junio de 1.946 el director aragonés, sin ninguna posibilidad de dirigir en Hollywood tras su exilio, decide marchar a Méjico. Fue requerido por la productora francesa Denise Tual para la realización de un proyecto sobre una versión de la obra lorquiana «La casa de Bernarda Alba». Pero finalmente Buñuel no podrá llevar a cabo la obra cinematográfica del poeta amigo debido a la imposibilidad por parte de la productora de adquirir los derechos de la pieza teatral ${ }^{1}$ de Federico García Lorca. Esa unión de los dos intelectuales españoles hubiese supuesto un importante homenaje del mundo cinematográfico a la generación del $27^{2}$.

Así pues, el único film del genial director español de ambiente andaluz es el basado en la novela del escritor francés Pierre Louÿs «La femme et le pantin», a la que Buñuel dio el título de Ese obscuro objeto del deseo.

La obra francesa ambientada en Sevilla había sido llevada anteriormente al cine en cuatro ocasiones. La versión primeriza la realizó Reginald Baker en 1.920 con Geraldine Farrar. La segunda, Jacques de Baroncelli, también en la época del cine mudo, y se dio a conocer en España bajo el título de «La muñeca y el pelele», siguiendo muy de cerca el título del original. En esta versión silente hacía de protagonista Conchita Montenegro, entonces en uno de sus mejores momentos.

La tercera aportación cinematográfica, más interesante, sería realizada en Hollywood bajo la dirección del vienés Josef von Sternberg con la denominación The devil is a woman, apartándose del título original. Esta versión de Sternberg sería llevada a cabo en 1.935 y contaría con el protagonismo excelente de la actriz berlinesa Marlene Dietrich, que encarnaba a la mujer fatal. La obra cinematográfica de Sternberg causaría un grave incidente político. El Gobierno español de la II República la había considerado ofensiva y exigió a la productora Paramount la destrucción del negativo y de todos sus copias, amenazándola, de lo contrario, con clausurar la representación de la firma en Madrid y con la prohibición de proyectar todas sus películas en el territorio nacional. El argumento del Gobierno español era que una escena en la que un guardia civil bebía en un café público suponía una ofensa a las fuerzas armadas españolas. La productora norteamericana accedió aparentemente a esta exigencia el 11 de noviembre del mismo año. Sin embargo, y para bien de la cultura cinematográfica, la destrucción del negativo no se llevó a efecto. Actualmente existen copias de The devil is a woman en filmotecas de

1. Gubern, Román, Cine Español en el Exilio, Ed. Lumen, Barcelona, 1.976.

2. Gómez Mesa, Luis, «La generación cinematográfica del 27: Luis Buñuel su gran figura», en Cinema 2002, $\mathrm{n}^{\circ} 37$, marzo 1.978, Madrid. 
varios países.

Buñuel indudablemente conoció toda esa historia en su época y ello, tal vez, significó para él un motivo de estímulo. Pensó en una nueva versión para la pantalla e incluso llegó a escribir gran parte del guión. Sin embargo, dificultades de producción impidieron su propósito.

El cuarto proyecto cinematográfico sobre la obra del escritor francés no sería realizado por Buñuel, sino por Julien Duvivier y con el protagonismo femenino de Brigitte Bardot en el papel principal.

«Si el film de Stenberg era la exaltación romántica de la bailarina española en un clima de fetichismo, el de Duvivier representaba la versión morbosa de una pasión loca, desesperada y pesimista»³.

Así pues, el maestro del surrealismo, Buñuel, habrá de contentarse con la quinta adaptación ${ }^{4}$. Sin embargo, tendrá que esperar a 1.977 para llevar a cabo su visión en imágenes de la mujer fatal, esa «bestia andaluza» apasionada y calculadora. Pero el primer guión inacabado quedó en el recuerdo del director y aflorarían ciertos rasgos en sus filmes El diario de una camarera (1.964) y sobre todo en la excelente obra surrealista Belle de jour (1.967) y en Tristana, posteriormente.

En esos filmes las protagonistas femeninas se mueven entre la ingenuidad y la picaresca, entre la inocencia y la perversión, llevando entre sus fotogramas alguna sabia de la idea abandonada años atrás y que permanece en las neuronas del cineasta hasta que años después decide retomar y rehacer el guión polvoriento con la colaboración de Jean Claude Carriére.

\section{Un francés en Sevilla}

Pierre Louÿs ${ }^{5}$, artífice original del argumento de la película de Buñuel Ese obscuro objeto del deseo, fue un novelista popular de finales del siglo XIX y comienzos de éste. En sus escritos cultivó el género erótico, decadente y fantástico, con frecuentes escapadas a la antigüedad helénica y al orientalismo. La novelas del postsimbolista Pierre Louÿs, tan bien aprovechadas por el cine, han sido siempre centro de controversias intelectuales. Ya con la aparición de su obra «Las canciones de Bilitis», publicada en 1.894, se produciría el escándalo. Sobre sus defensores caería el apelativo de «inmorales». Entre esos defensores se encon-

3. Alcalá, Manuel, «Ese oscuro objeto del deseo», en Cinema 2002, no 37, Madrid, marzo 1.978.

4. Mario Camús realizó después otra versión, la sexta cinematográfica, con el título de la obra original interpretada por Maribel Verdú. Fue emitida por TVE el 22 de septiembre de 1.995.

5. Pierre Louÿs (Gand,1.870-París,1.925). A los dicinueve años conoció a Leconte de Lisle y trabó amistad con el poeta parnasiano José María de Heredia, con una de cuyas hijas terminó casándose, Louise, si bien había mantenido relaciones apasionadas con su otra hija Marie. Gran amante de los líricos griegos, sus primeros poemas aparecieron en «La Conque», revista fundada por él mismo. Sus obras más conocidas son: «La canciones de Bilitis», «Astarté», «Afrodita», «La mujer y el pelele» y «Sique», publicada póstumamente en 1.927. 
traba el conservador y católico Maurras, que pensaba que la obra era una «joya» ${ }^{6}$. Incluso un escritor contrario a Maurras, Anatole France abogaría en defensa de Pierre. Sin embargo, para el crítico cinematográfico y literario español Luis Quesada, en el novelista francés «no hay que buscar profundidad temática ni certera introspección psicológica en los personajes» ${ }^{7}$. Brillante y auténtico para unos, falso y aburguesado para otros, Louÿs ha sido siempre un autor controvertido. Sus obras buscaban personajes sorprendentes, brillantes y disparatados, situaciones tópicas o inesperadas, colorido y fantasía. Todos esos ingredientes incluye en «Le femme et le pantin», publicada en 1.898.

Pierre Louÿs pasó dos temporadas en Sevilla (1.895 y 1.896), tanto por razones médicas al padecer trastornos pulmonares, bronquitis, como por razones artísticas, debidas al recuerdo y a la fascinación que despertaba en él la obra «Carmen», de Mérimée y Bizet. La ópera de Bizet la mantenía íntegra en la memoria, e incluso él mismo la tocaba al órgano. Uno de esos días que interpretaba a Bizet encontró el tema de «La mujer y el pelele». «Pensaba muchas veces en el libro que podía obtener acerca del carácter de la mujer, considerado desde el punto de vista de Carmen, pero de una Carmen más sutil, más inteligente, más atrozmente mujer. Pues en Carmen (de Mérimée) a menudo es la bestia humana la que actúa ${ }^{8}$. A pesar de que la gestación de la novela fue larga, en seis días escribió más de la mitad del libro y después de 60 páginas de redacción paró en brusco su producción, al llegarle la noticia de que Marie de Heredia, la mujer que amaba y que llevaba un niño suyo, se casa con el poeta Henri de Régnier. Asustado, marcha con precipitación hacia Egipto.

La primera vez que visitó la ciudad hispalense, a los 25 años, la disfrutaría durante tres meses, tras la publicación de «Las canciones de Bilitis». En la siguiente temporada el escritor ya se ha hecho célebre por su obra «Afrodita». En marzo de 1.898 vuelve a la redacción de su novela y la termina. Tuvo que hacer hablar en la obra a un personaje que no tenía sus gustos, su actitud hacia las mujeres, ni su edad, ni su manera de comprender la vida. El mismo escritor reconoció que no volvería a hacerlo más. Su composición «La femme et le pantin», libro célebre, probablemente el mejor que haya escrito según algunos estudiosos literarios, habrá de ser su mejor recuerdo sevillano, siendo una sorpresa que impresionó a los lectores.

6. Armiño, Mauro, Parnaso Diccionario Sopena de Literatura, Ed. Ramón Sopena, Barcelona, 1.972.

7. Quesada, Luis, en La estafeta literaria, $\mathrm{n}^{\circ}$ 635, Madrid, 1.978.

8. Cardinne-Petit, R., secretario de Louÿs, citado por Goujon, Jean-Paul y Camero Pérez, $\mathbf{M}^{\mathrm{a}}$ del Carmen en Pierre Loü̈s y Andalucía. Cartas inéditas y fragmentos, Ediciones Alfar, Sevilla, 1.984, pág. 19. 


\section{La adaptación cinematográfica}

Ese obscuro objeto del deseo, única obra postfranquista de Buñuel, basa sus líneas maestras en la popular y brillante novela de Louÿs, con un guión escrito por el propio Luis Buñuel y su coguionista Jean Claude Carriére y fue la película candidata española nominada para el Oscar de 1.978, a pesar de que sólo una quinta parte del capital con el que se hizo la cinta era nacional. Sin embargo, esa pequeña aportación del productor Alfredo Matas, y el añadido de los escenarios y los actores, hace que el filme se incluya dentro del cine español. La película, a pesar del prestigio de sus autores y de que la adaptación del texto a la pantalla grande fue llevado a cabo recreando una mayor hondura y dimensión psicológica de los personajes, no logró alcanzar el preciado galardón.

Katherine Kovács, en un ensayo sobre el filme, apunta que «desde el punto de vista del argumento, los personajes, los incidentes y el diálogo, la película es una adaptación fiel de 'La femme et le pantin'»' . En la misma línea se manifiestan Jean-Paul Goujon y $\mathrm{M}^{\mathrm{a}}$ del Carmen Camero Pérez.

Se advierte en la realización de la cinta una gran preocupación del director por la forma, utililizando una construcción ordenada, coherente, lineal, si bien la adereza con un conjunto de seis «flash-back» para agilizar la narración y volverla al tiempo real de cuando en cuando. En resumen un estilo clásico y preciso, claro y comprensible, tratado con desenfado y erotismo: un poema que canta a la perversión elegante y refinada.

El contenido del guión, a pesar de seguir de cerca la obra de Louÿs, presenta cierta originalidad y se aparta en gran medida tanto de la estructura como del estilo de la obra francesa e igualmente presenta derroteros diferentes de las otras versiones cinematográficas.

El mismo Buñuel sostuvo que lo más importante de una narración es el suspense. Así que una vez que Mateo haya poseído a Conchita, el interés en la historia decaerá ${ }^{10}$.

La película, ya antes de su producción, había despertado el interés de los cinéfilos: tanto de los contrarios como de los incondicionales del director de Calanda. Muchos críticos llegaron a hablar de un rejuvenecimiento intelectual y cinematográfico de Buñuel. Y es que la lógica y la ilógica narrativa de Ese obscuro objeto del deseo seguía rindiendo homenaje a los postulados surrealistas del cineasta.

9. Kavács, Katherine, «Luis Buñuel and Pierre Louÿs: Two Visions of Obscure Objects», en Cinema Journal, vol 19, núm 1, 1.979, págs 87-89, citado por Hopewell, John, en El cine español después de Franco, Ed. El Arquero, Madrid, 1.989, pág. 308.

10. Hopewell, John, Op. cit., pág. 309. 


\section{Una historia entre París y Sevilla}

Ese obscuro objeto del deseo es la historia de Conchita, una joven andaluza que es la tortura y la ilusión de Mateo. En clave de flash back, se inicia en el tren Sevilla-París. Es la huida de la situación que ha vivido Mateo. En la sevillana estación de Córdoba aparece la andaluza, pero los nervios del protagonista están ya destrozados: le vierte un cubo de agua en la cabeza. Los pasajeros del tren están perplejos, interesándose en la historia. "Esa mujer es la peor de las mujeres», confiesa el viajero.

La andaluza va a servir a casa de Mateo, en París. Esa misma noche el hombre maduro intenta besar a la dieciochoañera a la que no le gusta trabajar, sólo bailar. A la mañana siguiente ella se ha despedido.

Mateo busca a Conchita, que le tiene fascinado, asiste a los ensayos de baile y le lleva regalos y dinero. Ella le comunica que es «mocita» y le ofrece un caramelo, resistiéndose a concederle el amor carnal. En su juego y en su ambigüedad, a partir de ese momento, tan pronto es prometedora y ardiente como caprichosa y huidiza. Conchita desarrolla un juego atormentado que destroza la tranquilidad de su enamorado, precipitándolo hacia una situación insoportable de contradicciones, desdenes y promesas incumplidas.

Mateo, que nunca ha poseído a una mujer sin quererla apasionadamente, respeta demasiado el amor para frecuentar las trastiendas. Se resiste a pensar en que lo de ella sea por dinero. La andaluza le promete ser su amante en la casa de campo parisina. «¿Cuándo, ésta noche?». «No, mañana». Una vez allí Conchita le comunica que no se encuentra bien. Sin embargo, le enseña lo hermoso que es su cuerpo desnudo ante el espejo. Mateo pierde la paciencia al sentirse burlado con sus caprichos. Ella juega con el viudo. En la cama, descubre que Conchita lleva puesta una faja llena de lazos y nudos. Conchita le pide paciencia: «A ti lo que te gusta es lo que no te doy». "Si te diera todo lo que me pides dejarías de quererme». Mateo se enfada verdaderamente y la expulsa de casa.

Luego va a buscarla de nuevo a Sevilla, encontrándola en el Barrio de Santa Cruz. Descubre que baila desnuda en un club para turistas. Tras el enfado, Mateo, convertido ya en pelele, le compra una casa a la andaluza. Una vez en poder de Conchita las escrituras, lo humilla haciendo el amor ante él con un joven guitarrista.

A la mañana siguiente ella le declara que el guitarrista es marica: sólo estaban fingiendo. Aún es virgen. Mateo, desesperado ya, la deja tras darle una paliza.

De nuevo en el tren, Conchita le tira otro cubo de agua a Mateo. Vuelven a reconciliarse y pasean por Madrid. Él observa fascinado a una costurera que cose unas ropas manchadas de sangre. Nueva pelea. Finalmente, estalla una bomba terrorista que llena de humo la pantalla para acabar la película. 


\section{Dos caras para un personaje}

Antes del rodaje de la película su productor francés Silberman pretendía que la interpretación femenina corriera a cargo de la actriz María Scheneider, de reconocido prestigio en la época. Pero el director aragonés se había decantado por la española Angela Molina.

Sin embargo, poco antes del inicio del rodaje el anárquico Buñuel decidió repartir el papel principal femenino entre dos actrices: la española Angela Molina y la francesa Carole Bouquet, debido al dualismo temperamental de la protagonista, a los dos aspectos contradictorios de la personalidad y de la conducta de la andaluza. Por un lado Conchita era ardorosa e incitante, por otro esquiva y huidiza.

Ese reparto de interpretes para un único papel era nuevo en el planteamiento narrativo cinematográfico y un efecto visual y de realización interesante. Pero la decisión, de última hora y a guión escrito, no tuvo una plasmación narrativa plena $^{11}$. Con más tiempo, trabajando el guión y diferenciando claramente los dos temperamentos contrapuestos de la andaluza, el resultado hubiese sido más satisfactorio y brillante.

Tal como queda la película, por la precipitación de la decisión brillante del surrealista, el desdoblamiento de la personalidad queda oscuro para el espectador y el cambio de actrices resulta casi caprichoso. Ni la parte que corresponde a Angela Molina, espléndida en su interpretación, es exclusivamente ardiente y provocativa, ni la acción psicológica de Carole Bouquet, correcta y cumplidora, es totalmente esquiva y calculadora. Por ello, a veces, el planteamiento es desconcertante. Así pues, a nivel de guión el hecho de dos caras para un mismo papel llegó a ser irrelevante, y muchos espectadores no lo entendieron. La obra se alejó de esa manera un tanto del gran público, si bién recibió buena acogida comercial.

\section{La aportación surrealista}

El título del filme, sugestivo, poético y surrealista, no es idea original del autor de Calanda, sino que está extraído de un pasaje del escritor francés. A Louÿs era lo que menos le gustaba de su novela y el título «La mujer y el pelele», inspirado en un tapiz de Goya, lo consideraba una «humorada». No le gustaba que el papel de Don Mateo estuviera suficientemente definido por la palabra «pelele». Sin embargo no lo cambió. También barajó los títulos «La sevillana» y «La andaluza». El propio Louÿs hablaba de «esos pálidos objetos del deseo» de las mujeres rubias. Esa idea que tuvo entre los dedos Louÿs y que ha atrapado Buñuel,

11. Los pormenores de las razones comerciales de la elección final de las dos actrices las cuenta Manuel Alcalá en Cinema 2002, n 37, Madrid, 1.978. 
cambiando la expresión «pálidos» por «obscuro», es, desde luego, bastante más interesante como título.

Buñuel introduce en su obra, como es consustancial a él, ciertos elementos surrealistas y obsesivos: un saco, un ratón, una mosca, una gitana que lleva por niño un cochinillo, el bastidor de la bordadora al final, y que recuerda al cuadro de Vermeer «La encajera»; así como numerosas referencias a noticias y atentados terroristas que van dándole a la película la personalidad del autor, esa chispa creativa y diferenciadora que marca el límite entre una obra mediocre y otra excepcional. Los atentados apuntan el clima de inseguridad del mundo contemporáneo.

Algunos otros elementos menores son introducidos por el director cinematográfico como el cubo de agua, recordando las bromas de su juventud en la Residencia de Estudiantes; o el tren, no presente en la obra de Louÿs. Todos esos recursos, escritura automática la mayoría de ellos, le permite distanciarse de la intriga. Esos elementos no responden al análisis razonado. Son sobre todo «súbitas inspiraciones» $\mathrm{o}$ «imágenes compulsivas» ${ }^{12}$ del realizador.

\section{La realización serena}

El montaje de la cinta, aun con varios «flash-backs» narrativos, elude todo tipo de complicaciones técnicas, basándose sobre todo en una cámara en movimiento y con planos largos donde los actores desarrollan su personaje. Esa es su técnica desde que comenzó en el cine y está tan seguro de ella que no se deja impresionar por los nuevos hallazgos. Buñuel no necesita en el filme efectos visuales inusitados para subrayar las evidencias narrativas. Confía en su visión de la dirección de actores. Posee una extraordinaria seguridad en su escritura y en su mirada cinematográfica. Tal vez para el cineasta únicamente cuente el significado de la imagen, dejando al margen cualquier tipo de esteticismo vacío, o de perfección técnica. Incluso existe un «salto de eje» que cambia la dirección del movimiento en la secuencia del grupo que acompaña al cura por las calles nocturnas del Barrio de Santa Cruz. Esa ruptura del "eje imaginario" en otro director hubiese sido una herejía de lenguaje cinematográfico. Sin embargo, Buñuel no le da importancia.

En el rodaje, rara vez repitió una toma, como era habitual en él, de tal forma que Ese obscuro objeto del deseo salió ya montada desde su filmación. Helene Plemiannikov, que se encargó del montaje, comprendió la idea del director, y dio

12. Declaraciones de Buñuel, en Luis Buñuel, obra cinematográfica, de Sánchez Vidal, Agustín, Ediciones J.C., Madrid, 1.984. 
forma definitiva a una yuxtaposición de planos casi matemática. La aportación al cine de Buñuel es más narrativa que técnica.

"En lo formal -montaje, ritmo, planificación, etc.- las películas del director aragonés son logros rotundos. Se le ha criticado que se preocupaba poco de la fotografía, especialmente en su etapa mexicana, pero en realidad de lo que se ocupaba poco era de hacer tarjetas postales con los encuadres, de crear belleza artificial. La plástica de sus filmes responden al fondo de los mismos, por ello es sobria y nunca se entretiene en describir mas de lo necesario. El ritmo nunca es lento ni se remansa, como en Bergman o Visconti, por eso los metraje no suelen rebasar los noventa minutos. Cada secuencia atrae de modo preciso, tiene las imágenes justas, en un proceso de elipsis... Es un cine rápido, vital, cargado de una energía que poseen los grandes maestros de Hollywood, a quienes tanto admiraba... En los actores inyecta su poderoso carácter." 13

Así pues, como vemos, ni el montaje, ni el ritmo dentro de ese montaje de imágenes, deben nada al popular cine americano, aunque admirase a algunos de sus directores. Pero tampoco los encuadres, ni la dirección de actores. Todos los recursos son de aportación personal, imbricados en la cultura europea y especialmente española. Su cine es una visión del mundo muy íntima, pero también muy sobria, que huye del esteticismo vacío.

\section{La Sevilla de Buñuel:}

La representación sevillana en la película viene dada en diferentes secuencias. El filme se abre con una calle en la que aparece de fondo el comercio hoy desaparecido «El Corte Español», de moda en la capital hispalense en los momentos del rodaje, y que se anunciaba con el mismo estilo y color de letra que su competidor «El Corte Inglés». Le sigue poco después un atentado en el Parque de María Luisa, al introducirse el productor de la película, Serge Silberman, en un lujoso coche. Mateo, que contempla la explosión y comenta extrañado «¿aquí también?», vive en una espléndida mansión de la avenida de La Palmera, como corresponde a su elevada condición social y económica. A continuación la Estación de Córdoba, hoy reconvertida, construida entre 1.898 y 1.901, por los ingenieros Santos Silva, portugués, y Suárez Albizu, vasco, de estilo neomudejar y con aplicación de la técnica utilizada en el XIX para la construcción de la Torre Eiffel del hierro fundido. Sin embargo, a Buñuel no le interesa el hierro de la arquitectura, sino el metal del tren y sobre todo la frialdad y el resentimiento a que han llegado los protagonistas. Ese es el bloque de la primera parte sevillana.

13. Pérez Bastías, Luis, en Las dos caras de Luis Buñuel, Royal Books, Barcelona, 1.994, p.76. 
Avanzado el argumento de la cinta Mateo vuelve tras su estancia en París y en Suiza. Es entonces cuando la presencia del decorado de la ciudad andaluza se hace más intenso. Aparece en primer lugar, en panorámica, la terraza del restaurante del antiguo Hotel Luz Sevilla, donde hoy se encuentra un bloque de apartamentos y las oficinas de El Monte, arriba del Pasaje de Villasís. Al fondo, una vista de la ciudad en la que van apareciendo, en plano general, la Iglesia de la Universidad con la Facultad de Bellas Artes y un palacete en primer término; y después, para acabar la panorámica descriptiva, se queda con la Iglesia de El Salvador, a la izquierda, y la Catedral a la derecha, en una magnífica composición fotográfica. Planos parecidos desde otras terrazas se utilizan hoy día para anuncios publicitarios. Le sigue, en otra secuencia, lo que podríamos considerar el único plano documental, aislado, de Sevilla, sin personajes: La Giralda y la Catedral en contrapicado, mientras Mateo comenta: «¿Qué maravilla, verdad?». A lo que el criado responde: «Con franqueza, señor, no entiendo mucho de arquitectura». $\mathrm{Al}$ inicio de esta escena, rodada en el Patio de Los Naranjos, aparece en plano general un coche de caballos con un sonido potenciado en primer plano de los cascos golpeando el suelo. Por la noche Mateo busca a Conchita en el Barrio de Santa Cruz y se cruza con un cura acompañado de unos monaguillos y un grupo de mujeres enlutadas. A continuación, en el tablao flamenco Conchita baila desnuda para japoneses. Es otro de los aspectos surrealistas más logrados de la película y que mayor impresión causaron. Esa escena Louÿs la localiza en el Burrero: «baile de gitanas en el que bailaba la Macarena cuando la han cogido para la Exposición». Buñuel pone en boca de su protagonista: "Qué inocente. Que se baila desnuda para los turistas hasta los niños lo saben». La secuencia cumbre de la película, que lleva al derrumbamiento psicológico del personaje, se desarrolla ante la reja de un patio sevillano del Barrio morisco de Santa Cruz al que llega Mateo después de pasar el callejón del Agua. Los escenarios, como vemos, son los típicos de la ciudad del sur y la aportación a la imagen de Andalucía puede parecer reiterativa.

Tal vez sea que Sevilla, para Buñuel, al igual que la protagonista de su cinta, tiene, como expresa Joaquín Romero Murube, «algo de encanto femenino. Nos gusta y no sabemos por qué, y de ahí su irresistible atracción. Es íntima, difícil, tierna, misteriosa, desconcertante» ${ }^{14}$. 


\section{Conclusión}

El paso del tiempo, el análisis sosegado y una observación minuciosa con la nueva técnica del vídeo viene a poner en su lugar la apreciación de la película. Las críticas adversas de la época fueron relevantes visto desde un análisis de Andalucía. Si en el plano cinematográfico tiene aciertos de importancia, hallazgos de interés, en la faceta de la visión sevillana, en una percepción primeriza y precipitada, pudiera parecer que la sustancia que aporta no es original, perdiéndose en el tópico sureño, en la imagen repetida, en una Andalucía, una Sevilla, real sí, tal vez, pero una y mil veces vista, adocenada, turística. Sin embargo, la profundización en el filme viene a vislumbrar nuevas miradas del cineasta aragonés que realiza ciertos guiños inteligentes al espectador para despegarse del tópico común, como en las secuencias del baile para japoneses, o la gitana en el Patio de los Naranjos con su «churumbel»-cochinillo; igualmente el atentado en el Parque de María Luisa, o esa escena cumbre de la reja, de artística forja, que deja entrever la risa y la perversidad de Conchita. Y es que el perverso Buñuel, que escribió su testamento cinematográfico con esta obra, es capaz de reírse también de los lugares comunes. Se deja seducir por Sevilla y utiliza los tópicos para transcenderlos.

\section{FICHA ARTÍSTICO-TÉCNICA ${ }^{15}$}

Título: ESE OBSCURO OBJETO DEL DESEO.

Año de producción: 1.977

Alfredo Matas presenta en España

Ese obscuro objeto del deseo.

Un film de Luis Buñuel

Argumento: Luis Buñuel en colaboración con Jean Claude Carriere.

Inspirado en la obra de Pierre Louÿs «La femme et le pantin», ediciones Albin Michael.

Intérpretes: Fernando Rey

Angela Molina

Carole Bouquet

Julien Bertheau

María Asquerino

Andre Weber

Milena Vunotic

Ayudantes del director: Pierre Lary

15. Esta ficha se presenta tal como lo hacen los títulos de la película original. 
Juan Luis Buñuel

Jefe de montaje: Helene Plemiannikov

Decoración: Enrique Alarcón

Pierre Guffroy

Director de fotografía: Edmond Richard

Dirección de producción: Ully Pickard

Un film producido por Serge Silberman

Igualmente interpretado (por orden alfabético): Ellen Bahl, Valérie Blanco, Auguste Carriere, Roberto Cruz, Jacques Debary, Antonio Duque, Claude Jaeger, Andre Lacombe, Lita Lluch-Peiro, Anni Monange, Muni, Bernad Musson, Pierai, Isabelle Rattier, David Rocha, Remigo Sacristán, Isabelle Sadoyan, Juan Santamaría.

Vestuario de Fernando Rey: Francisco Smalto (París)

Vestuario de Angela Molina y Carole Bouquet: Chice (París)

Ingeniero de sonido: Guy Villette

Ayudante de sonido: Olivier Villete

$2^{\mathrm{o}}$ operador: Jean Harnois

Ayudantes de cámara: Philippe Houdart

Alain Herpe

Julio Leiva

Fotógrafo: Jean Distinghin

Scrip: Suzanne Durrenberger

Ayudante de decoración: Claude Moesching

Mueblista: Pierre Lefait

Regidor de exteriores: Jean Revel

Efectos especiales: Francois Sune

Jefe de maquillaje: Odette Berroyer

Peluquería: Jean-Pierre Berroyer

Jefe de vestuario: Sylvie de Segonzac

Ayudantes de vestuario: Mimi Gayo

María Teresa García

Producción: Gille Schneider

Carlos Ramón

Ginette Billard

Administración de producción: Jacqueline Dudillux

Santiago de Benito 